\title{
A Maçã e o Biscoito da Sorte
}

\author{
The Apple and the Fortune Cookie \\ Luciano da Fontoura Costa \\ Grupo de Pesquisa em Visão Cibernética \\ IFSC, Universidade de São Paulo \\ luciano@if.sc.usp.br
}

Recebido em 25 de outubro, 2002. Aceito em 16 de abril, 2003.

\begin{abstract}
Após motivarmos o método científico como a maneira mais promissora de aquisição de conhecimento e previsão, discutimos como o mesmo estará sendo revisto sob a perspectiva de aplicações em biologia.
\end{abstract}

After reviewing the scientific methods as the most promising means for knowledge acquisition and prediction, we discuss how it is being changed in order to be more effectively applicable to biological problems.

\section{Em solo mágico}

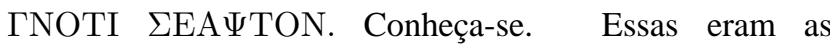
enigmáticas palavras que saudavam os visitantes na entrada da fonte Castália, parada obrigatória para purificação antes do acesso ao templo de Apolo, em Delfos. Reza a lenda que o local deste famoso centro de peregrinação, um dos poucos elementos unificadores da antiga Grécia, foi determinado ao se soltar duas águias, cada uma num dos confins da Terra. O ponto onde se encontraram teria assim determinado o centro do nosso planeta, que foi devidamente marcado com a estranha rocha denominada omphalos, o umbigo do mundo. Verdade ou não, Delfos permanece um lugar de singular beleza e mistério, fundado solidamente numa imponente montanha de granito vermelho, o Parnaso, sonhando eternamente com o fugidio limite entre os azuis do céu e do mar do Golfo de Corinto. A tudo isso observavam os muitos viajantes que, como as famosas águias, aqui chegavam das mais variadas e distantes partes do mundo antigo. Vinham em busca da mais valiosa das mercadorias: o futuro. Qual a situação mais propícia para construir uma casa ou ter um filho? Quando fundar uma nova colônia? Qual o melhor cultivo para a próxima estação? Os Corintianos ganharão as próximas olimpíadas?

Sentada sobre um tripé, numa sala inferior do templo de Apolo, após mascar folhas de louro, a pítia entrava em transe, auxiliada pelos vapores que emanavam de fraturas no solo. Enquanto neste estado, respondia às diversas questões sobre o futuro, escritas em cacos de cerâmica pelos aflitos peregrinos. Como suas respostas eram quase sempre muito enigmáticas, todo um comércio voltado para a interpretação dos oráculos se estabeleceu ao redor do templo. Uma previsão particularmente famosa foi aquela dada ao rei Creso, da Lídia, que, ao indagar sobre se devia invadir o território persa, obteve a resposta de que um império poderoso seria destruído em consequiência. Tendo interpretado tal oráculo como um bom presságio, Creso levou sua campanha a cabo, o que resultou em amarga derrota. Para muitos ficou então claro que o reino que seria destruído não era a Pérsia, mas o do próprio Creso. Para alguns poucos outros, o que tem ficado claro é que o verdadeiro segredo dos oráculos é o seu elevado grau de subjetividade e ambigüidade e, conseqüentemente, versatilidade, aliado à vontade de acreditarmos nos mesmos.

A longa atividade do oráculo de Delfos estendeu-se até o século IV, quando o mesmo se auto-declarou extinto. Desde então, a importância do futuro permanece tão forte quanto antes, tendo mesmo se intensificado a ponto de os humanos continuarem a recorrer a todos os possíveis subterfúrgios para essa finalidade. Horóscopos, búzios, bolas de cristal, tarot, runas... Embora a lista dos sucessores de Delfos seja praticamente infindável e sempre crescente, um deles destaca-se brilhantemente: a ciência. Isso mesmo, para surpresa de muitos, o mais bem sucedido mecanismo de previsão do futuro não é o biscoito da sorte, mas a ciência e a sistemática atividade de construção de modelos que a orienta. Nas linhas seguintes vamos revisar e discutir como a ciência se relaciona estreitamente com a previsão do futuro, identificando sua fundamentação matemática, suas vantagens e limitações, assim como as peculiaridades do seu uso para os estudos em biologia e genética.

\section{A estreita ponte entre a realidade $e$ abstração}

Embora fundamentalmente diferente, a ciência moderna apresenta uma analogia marcante com oráculos e outros equivalentes. Enquanto lá o futuro é buscado através do contacto com o mundo dos espíritos ou deuses, na ciência a busca é feita no mundo igualmente imaterial da abstração lógica e matemática, que fornece as bases para a formalização e validação do conhecimento científico. De fato, a matemática desfruta de posição ímpar dentro das ciências, pois é apenas aí que fatos podem ser estabelecidos 
definitivamente. Uma vez provado (corretamente), um teorema é para sempre. Para sempre, exceto em situações de grande complexidade, como o teorema de Fermat, quando erros humanos tendem a se tornar inevitáveis. A aplicação da matemática na explicação e previsão dos fenômenos naturais iniciou-se com a física e estendeu-se logo para a química, estando às portas da biologia e medicina [1-4]. Hoje em dia, perspectivas sem precedentes para o avanço científico estão sendo delineadas pelo uso sistemático da matemática nessas áreas.

Mas, de que forma é então tipicamente feita a conexão entre um fenômeno do mundo real sob estudo e o da abstração matemática, levando a um modelo do fenômeno observado? O primeiro passo (veja a Figura 1) consiste em se identificar as variáveis mais relevantes do fenômeno sob análise, de forma a se obter uma representação do mesmo. Por exemplo, a população de Governador Valadares ao longo dos anos pode ser representada como a variável $p(t)$, onde $t$ é o tempo. Em seguida, precisamos considerar relacionamentos matemáticos significativos, geralmente através de uma ou mais equações, entre as variáveis envolvidas, que possam não apenas reproduzir os dados observados, mas também levar a previsões sobre o comportamento do fenômeno no futuro ou em condições diversas. Esta fase, que denominaremos construção do modelo, freqüentemente envolve o uso de diversos teoremas e conceitos matemáticos como forma de se produzir equações e representações mais simples e/ou efetivas. O modelo assim obtido deve então ser validado, o que pode ser feito comparando-se resultados gerados através simulações do modelo com uma quantidade significativa de dados experimentais. Como quase sempre acontece, discrepâncias são identificadas na fase de validação, levando a uma repetição dos passos anteriores e a uma consequente revisão do modelo matemático. De volta à prancheta de desenho, como diriam alguns personagens dos quadrinhos.

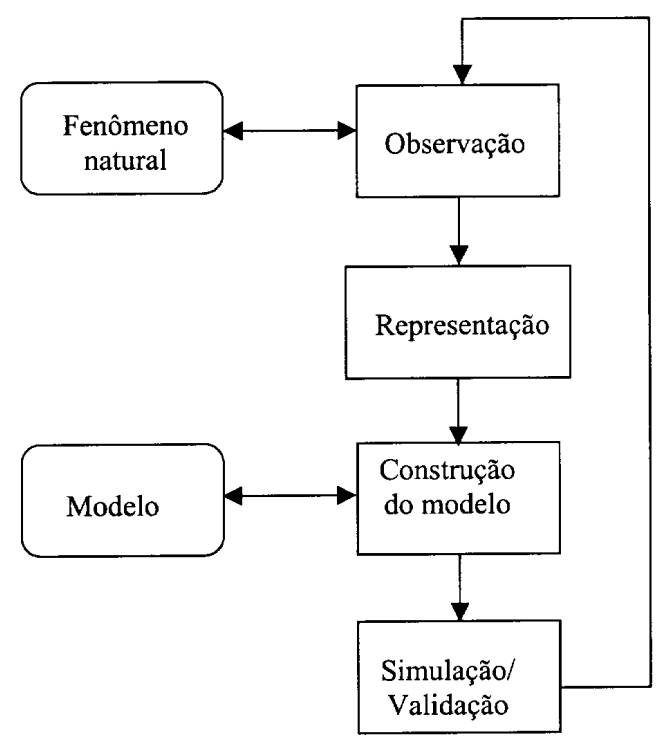

Figura 1. Principais passos no desenvolvimento e validação de modelos científicos.

O procedimento delineado no parágrafo anterior é normalmente denominado método científico que, como toda criação humana, apresenta aspectos fortes e fracos. No primeiro caso, temos a relativa segurança e objetividade nas manipulações da representação do modelo permitida pelo uso da matemática e a fase de validação sistemática do funcionamento do modelo frente aos resultados experimentais e previsões confirmadas. Além disso, modelos e simulações representam uma forma muito econômica de se ensaiar situações práticas (por exemplo o comportamento de um avião ou foguete sob condições extremamente adversas). O primeiro ponto fraco origina-se da escolha relativamente arbitrária e necessariamente incompleta dos aspectos do fenômeno a serem considerados. Embora o tratamento matemático possa levar a resultados definitivos no domínio da abstração, a representação do fenômeno é, inevitavelmente, incompleta. Por exemplo, um modelo completo de um relógio de pêndulo precisaria levar em conta não apenas seu comprimento e massa, mas também o efeito da gravidade das pessoas à sua volta, ou mesmo da massa da Lua e de outros planetas, estrelas, cometas, ou galáxias. Outro exemplo são os modelos de movimento planetário que desconsideram o relevo e outros detalhes de cada planeta (veja a Figura 2). A consequiência

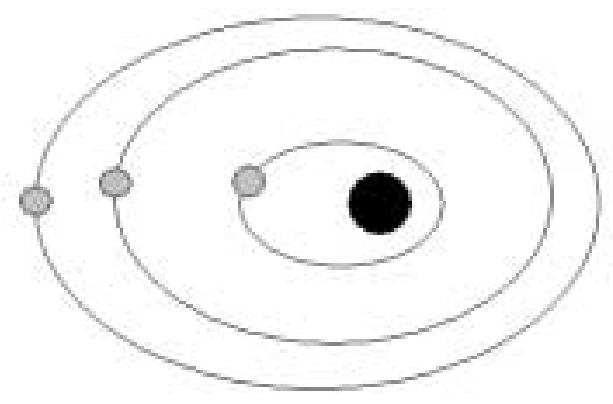

Figura 2. Os modelos científicos sempre envolvem representações incompletas da realidade. Por exemplo, modelagens típicas dos movimentos planetários no nosso sistema solar freqüentemente desconsideram a presença do relevo dos planetas, assim como muitos outros fatores.

mais séria dessa incompleteza, conhecida mais formalmente como degeneração, na modelagem é que os resultados simulados tendem a se desviar dos experimentais, especialmente ao longo de períodos mais longos de comparação. Em outras palavras, a degeneração reduz o potencial de previsão e explicação dos modelos. A segunda fraqueza do método científico é que, na maioria dos casos, não podemos validar os modelos desenvolvidos frente a todas as possíveis situações, que freqüentemente nem mesmo são conhecidas. Uma terceira limitação não se origina propriamente dos modelos, mas da nossa própria natureza humana. Em outras palavras, alguns cientistas (talvez muitos) acabam adquirindo "ligações afetivas" com seus arduamente desenvolvidos modelos, o que pode levar a ignorar desvios importantes ("os pontos fora da curva") ou enfatizar o potencial da abordagem. Entretanto, apesar dessas limitações que devem sempre ser levadas em conta, o método científico ainda é o mais bem sucedido mecanismo para a extensão do nosso conhecimento e previsão do futuro. De fato, um aspecto particularmente interessante do uso da matemática em modelagem científica é a extrema precisão que a mesma tem permitido na reprodução e previsão de inúmeros fenômenos naturais, das órbitas dos corpos celestes ao comportamento 
de neurônios. Seria o caso de a matemática ser o software executado pela natureza? Ou será que desenvolvemos a matemática de acordo com seus sucessos e fracassos verificados nas aplicações? Respostas a essas questões ainda não estão disponíveis.

\section{Como caem as maçãs}

Sendo a física a pioneira inconteste no uso sistemático da matemática para desenvolvimento de modelos bemsucedidos, é natural que qualquer abordagem científica, assim como em biologia e medicina, considere primeiramente os conceitos e métodos adotados nessa área. Ao assim fazermos, uma das primeiras coisas que logo se evidencia é que boa parte da metodologia nesta área fundamenta-se em modelos envolvendo equações diferenciais. A grosso modo, este tipo de equação é caracterizado pela presença de derivadas, elementos que indicam a taxa de variação dos valores representados no modelo. Um característica fundamental de tais variações é que elas ocorrem em intervalos muito pequenos de tempo ou espaço. Por exemplo, a velocidade, que expressa a variação da posição de um corpo em movimento em relação ao tempo, reflete o comportamento do mesmo numa vizinhança muito pequena de cada instante (velocidade instantânea). Como boa parte dos fenômenos estudados pela física, ao menos nas suas fases mais iniciais, envolviam a observação do comportamento ao longo de pequenos intervalos de tempo ou espaço, é natural que os respectivos modelos apresentem uma natureza diferencial ou local. Como dois acontecimentos de um mesmo tipo, como a queda de maçãs, nunca são absolutamente idênticos na natureza, torna-se freqüentemente necessário o tratamento dos dados e equações em termos estatísticos, que é também comum em física.

Um outro aspecto importante de um modelo físico é a sua generalidade. Em outras palavras, é freqüente acontecer de diversos fenômenos poderem ser explicados por um mesmo modelo, como é o caso das leis de Newton, que descrevem tanto o movimento de uma maçã como de um planeta. Essa importante economia é o que se denomina unificação. A propósito, uma conjectura ousada levantada pelo prêmio Nobel em física Richard Feynman, é que a equação de Schrödinger, que descreve os fenômenos físicos sob a perspectiva quântica desde o big-bang, poderia explicar todo o universo existente, representando assim a unificação plena dos modelos naturais. Desenvolvimentos são freqüentemente realizados de forma analítica que, em princípio, não envolve o uso de computador, permitindo a obtenção de soluções de algumas das equações envolvidas nos respectivos modelos, especialmente no caso dos mesmos serem lineares. Basicamente, a propriedade de linearidade significa que a mudança causada no comportamento do sistema será proporcional à intensidade das perturbações do mesmo. Em outras palavras, podemos esperar que, num sistema linear, uma pequena perturbação implicará apenas em pequenas mudanças na sua dinâmica. Dessa forma, sistemas lineares (ou linearizados) favorecem previsões de mais longo prazo. Isso não é necessariamente verificado para sistemas não-lineares, onde pequenas perturbações podem ser rapidamente amplificadas ao longo do tempo ou espaço, levando a grandes alterações do comportamento do mesmo
[1,3]. Como apenas uma pequena parcela das equações diferenciais usadas em física pode ser resolvida analiticamente, o tratamento desses casos precisa ser feito de forma "numérica", utilizando-se computadores. Assim, o avanço da tecnologia de computação verificado ao longo da segunda metade do século passado veio a implicar uma da mais importantes influências para a ciência desde a formalização da matemática. Uma conseqüência disso foi o nascimento da área de sistemas dinâmicos, com ênfase para o estudo de modelos não-lineares, incluindo o caos (significando que o sistema apresenta grande sensibilidade a perturbações). Hoje em dia, raros são os pesquisadores em física que não se utilizam de computadores. Por sinal, até mesmo estudos analíticos em física vêm se beneficiando cada vez mais dessas máquinas.

Apresentamos a seguir um modelo simples, na forma de um sistema de equações diferenciais ordinárias, descrevendo a dinâmica entre as populações de presas, representada pela variável $x(t)$, e predadores, representada por $y(t)$. As quantidades $a, b, c$ e $d$ correspondem aos parâmetros do sistema de equações diferenciais, e as derivadas primeiras $\frac{d x(t)}{d t}$ e $\frac{d x(t)}{d t}$ expressam a velocidade, ou "tendência de aumentar ao longo do tempo" das respectivas variáveis $x(t)$ e $y(t)$.

$$
\left\{\begin{array}{l}
\frac{d x(t)}{d t}=a x(t)-b x(t) y(t) \\
\frac{d y(t)}{d t}=-c y(t)+d x(t) y(t)
\end{array} .\right.
$$

Este modelo diferencial, conhecido como LotkaVolterra, representa uma tentativa muito simplificada de se explicar as oscilações de populações de duas espécies de animais, uma predadora e a outra consumida, obtidas em consequiência da interação das mesmas ao longo do tempo. Os pontos de equilíbrio $\left(x_{e}, y_{e}\right)$ deste sistema podem ser determinados ao se impor que a velocidade se anula nesta situação. Além da solução trivial, isto é, $(0,0)$, temos como ponto de equilíbrio:

$$
\left\{\begin{array} { l } 
{ \frac { d x } { d t } = a x _ { e } - b x _ { e } y _ { e } = 0 } \\
{ \frac { d y } { d t } = - c y _ { e } + d x _ { e } y _ { e } = 0 }
\end{array} \Rightarrow \left\{\begin{array}{l}
x_{e}=c / d \\
y_{e}=a / b
\end{array}\right.\right.
$$

A simulação numérica do sistema acima pode ser obtida utilizando-se um método como o das diferenças finitas, que corresponde, grosso modo, a perseguir o estado do sistema por diversos passos de tempo tomando como direção a velocidade do mesmo. A Figura 3 apresenta uma simulação numérica do sistema acima considerandose $x_{0}=15, y_{0}=20, a=1, b=0.03, c=0.4$ e $d=0.01$. Enquanto os gráficos em (a) e (b) ilustram os valores de $x(t)$ e $y(t)$ ao longo do tempo, tais dinâmicas podem ser representadas, após eliminar-se o tempo, conforme o diagrama em (c), conhecido como espaço de fase. A evolução do sistema a partir de um ponto inicial neste espaço é denominada trajetória. Observa-se que o sistema comporta-se de forma periódica, em trajetória fechada, com a população de predadores e presas alternando-se ao longo do tempo. Observe que a população de presas tende a diminuir após o aumento da quantidade de predadores e que esta última tende a aumentar após um aumento do número de presas, conforme esperado. 
$x$
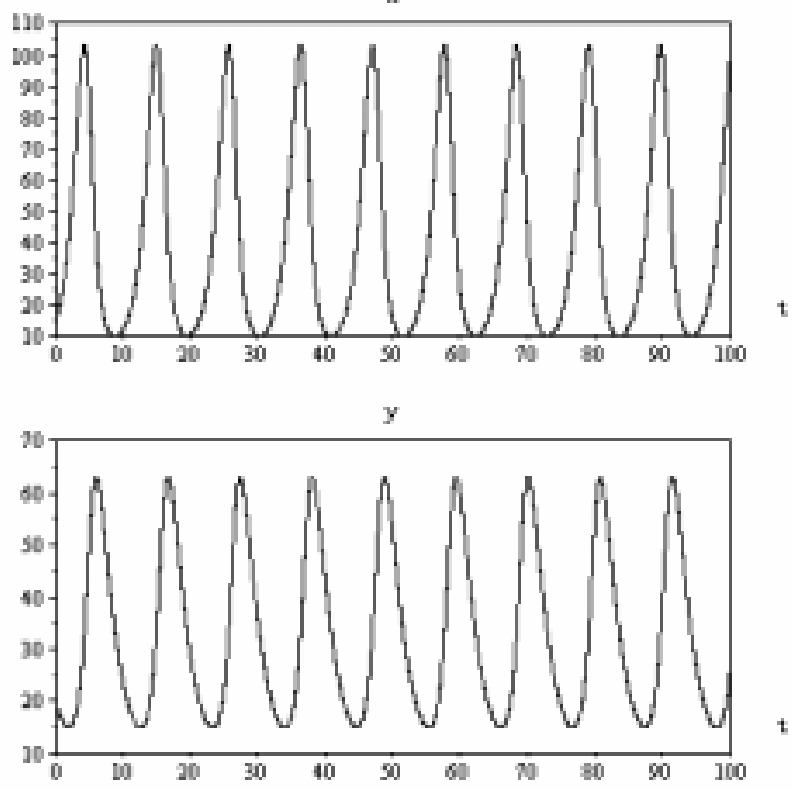

y

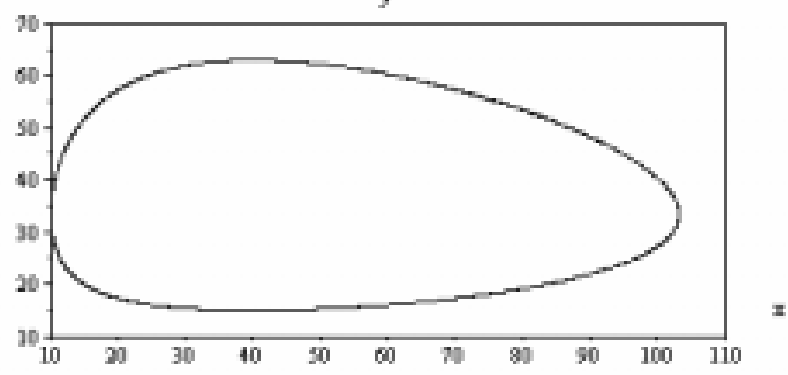

(a)

Figura 3 - Simulação numérica, através de diferenças finitas, da dinâmica do sistema Lotka-Volterra considerando-se $x_{0}=15, y_{0}=20, a=1, b=0,03, c=0,4$ e $d=0,01$.

Enquanto tais modelos envolvendo equações diferenciais ordinárias (EDOs) possibilitam-nos tratar de eventos nos quais a distribuição espacial das entidades observadas não é levada em conta, modelos mais completos exigem a representação do espaço, além do tempo. Tais sistemas podem ser convenientemente desenvolvidos utilizandose equações diferenciais parciais (EPDs), através das quais grande parte das leis físicas são expressas.

\section{O que os humanos possuem em co- mum com avestruzes?}

Uma importante pergunta imediatamente implicada por um estudo mais formal e matemático da biologia é o quanto das experiências em modelagem física pode ser imediatamente aproveitado. Em outras palavras, em que aspectos os fenômenos biológicos assemelham-se ou diferenciamse daqueles estudados em física? Primeiramente, como na física, os fenômenos biológicos apresentam variações (imagine quantas diferentes faces você conhece), que implicam naturalmente em métodos estatísticos para a descrição e tratamento dos dados experimentais. Abordagens diferenciais também têm sido comuns em biologia, embora os períodos de observação sejam um pouco mais longos (por exemplo, medimos populações ao longo de meses ou anos). Seriam a generalidade e unificação também importantes em biologia? Numa primeira instância, fica claro que muitos fenômenos biológicos apresentam comportamentos semelhantes, sendo portanto mais passíveis de serem unificados. Por exemplo, as equações que governam o movimento de um avestruz devem, em princípio, ser semelhantes àquelas que caracterizam o movimento humano, exceto talvez durante o carnaval. Entretanto, enquanto existem muitas oportunidades para unificar descrições de processos biológicos ocorrendo em períodos de tempo relativamente curtos, a situação se complica substancialmente quando tratamos de fenômenos se estendendo por longos períodos de tempo. Por exemplo, acredita-se que o sucesso dos mamíferos foi determinado pela queda de um meteoro há muito tempo atrás. A esses fenômenos incomuns e imprevisíveis, com implicações decisivas de longo prazo, o físico e prêmio Nobel Murray GellMann denominava acidentes congelados [1].

O problema é como incluir tais eventos em equações simples que descrevam a evolução da vida na terra. Não menos desafiador é obter uma representação simples dos genomas dos seres vivos utilizando poucas equações. A grande variabilidade dos dados e processos biológicos, assim como nosso limitado acesso aos acontecimentos passados, implicam no uso sistemático e decisivo não apenas de computadores em biologia, mas também de conceitos e métodos computacionais modernos como bases de dados, redes de computadores, reconhecimento de padrões e mineração de dados [5], assim como métodos multi-escala que permitam a divisão lógica dos diversos aspectos de um problema em termos de progressivas escalas de tempo e espaço (veja "A outra dimensão da dimensão fractal", Ciência Hoje, junho 2002). Evidências da assimilação inexorável da informática em biologia é a recente criação das áreas de $b i$ oinformática e neuroinformática, que se ocupam de conceitos e métodos computacionais para pesquisa sistemática em biologia/genética e neurociência [6], respectivamente.

\section{De volta ao futuro}

$\mathrm{Na}$ sua longa caminhada desde os tempos (e templos) de Delfos, os seres humanos realizaram feitos memoráveis e outros que melhor tivessem sido evitados. Estando agora no futuro daquele tempo, é fácil identificar, ao lado das artes, a ciência como uma das maiores realizações humanas. Ao contrário das abordagens místicas e oráculos, seus frutos são concretos, permanentes e abundantes. Além das comodidades do telefone celular (desde que não ativado durante a aula, diga-se de passagem), viagens aéreas e DVDs, a ciência já apresenta soluções para muitas das aflições humanas, fome e doenças incluídas, embora a iniciativa para tanto deva sempre partir de nós.

Ao voltarmo-nos para o futuro, questionamos sobre os próximos passos na caminhada humana. Como será a continuação do progresso científico? Asimov uma vez observou que a fronteira do nosso conhecimento seria um fractal [7]. Haverá assim um limite para o nosso conhecimento? De fato, uma das dificuldades que deverá se intensificar são as limitações do nosso próprio intelecto, que já tornam a 
compreensão de alguns modelos científicos mais modernos (por exemplo a mecânica quântica) extremamente desafiadora. Uma perspectiva relacionada nem sempre apreciada é que, em grande parte, nosso cérebro pode ser considerado o mais sofisticado modelador existente na natureza. Quem pode contestar que as chances de sucesso de cada indivíduo são fortemente definidas pelo seu respectivo potencial de previsão do futuro? Desde o início da jornada da humanidade, os caçadores mais bem sucedidos tem sido aqueles que melhor conhecem o comportamento dos animais, o que leva a melhores previsões de onde encontrá-los e à elaboração de melhores estratégias de tocaia. Em outras palavras, os mais bem-sucedidos caçadores são aqueles que possuem os melhores modelos do mundo natural. Talvez um dos fatores propulsores da evolução do nosso intelecto tenha sido a sofisticação cada vez maior necessária implicada por nossos hábitos sociais, atingindo um nível no qual precisamos elaborar modelos de outros humanos, de como eles nos vêem, e mesmo de como eles constroem modelos. Hoje em dia o cérebro humano continua a enfrentar o seu maior desafio, já pressagiado no tempo de Delfos, de conhecer-se melhor a si mesmo para, talvez, poder aprimorar-se. Através da ciência, é claro.

\section{Referências}

[1] Murray Gell-Mann. O quark e o jaguar, Rocco, 1996.

[2] Marting Gardner. O umbigo de Adão, Ediouro, 2001.

[3] J. Gleick. Caos: a criação de uma nova ciência. Campus, 1991.

[4] Freeman Dyson, Infinito em Todas as Direções, Companhia das Letras, 2000.

[5] L. da Costa e C. Montagnoli. Máquinas tomam decisões. Ciência Hoje, Out. 2001.

[6] L. da F. Costa, Maria C.F. Oliveira e Rosane Minghim. De olho no neurônio, Ciência Hoje, Dez. 2000.

[7] L. da F. Costa e A.G.C. A outra dimensão da dimensão fractal. Ciência Hoje, Junho 2002. 